\title{
Teaching with The Social Brain in Mind: A Neuroscientific Perspective on the Cooperation Spectrum
}

\author{
Gábor Braunitzer, $\mathrm{PhD}^{1,2,3,4}$; Gergely Tari ${ }^{2}$ \\ 1University of Szeged, Faculty of Medicine, Department of Physiology \\ 2University of Szeged, Faculty of Medicine, Department of Behavioral Sciences \\ 3University of Szeged, Faculty of Dentistry, Department of Oral Surgery \\ 4University of Szeged, Social Competence Research Group
}

\begin{abstract}
Neuroscience, with the wealth of information it has gathered about the human brain, might easily appear to be the scientific support education has always been looking for, over its centuries of mostly philosophically fueled experimentation. However, neuroscience is far from being some kind of panacea, which, once found, solves all problems of education in the blink of an eye, as some would like to look at it. The authors of this brief summary believe that neuroscience can become a powerful tool in the hands of education only if professionals of both fields speak both languages and understand each other's concepts. This summary is meant to be a kind of first sentence in that conversation, an introduction to the basic concepts of how the social brain works, and also a starting point for those who wish to further their knowledge in this field.
\end{abstract}

Keywords: social neuroscience, brain development, neuroscience in education, cooperation, aggression

\section{Introduction: can neuroscience inform education?}

An immensely long time has passed since Aristotle dismissed the brain as an organ of secondary importance, serving the sole purpose of cooling the body by its slimy secretions, and named the heart as the seat of all intellectual and emotional capacities (Gross, 1995). Although the idea was challenged every now and then over the centuries that followed, it was only relatively recently, with the neuroscientific boom of the twentieth century that we came 
to understand the real importance of this organ - and that Aristotle could not have been more wrong. From the establishment of the fact that neurons actually did exist by Golgi and Ramón y Cajal (in 1916) to the description of the neural basis of learning (i.e. neural plasticity) by Eric Kandel (in 2000), the twentieth century brought along a series of Nobel-winning neuroscientific discoveries so that today we can confidently claim that whatever we teach, we teach the brain.

Neuroscience, with the wealth of information it has gathered about the human brain, might easily appear to be the scientific support education has always been looking for, over its centuries of mostly philosophically fueled experimentation. But is it really? Can neuroscience inform actual curricula or at least give us practical hints rooted in 'hard science'? Opinions vary. Some are eager to say yes, and do not hesitate to make such hints commercially available. One well-known example is BrainGym ${ }^{\circledR}$, a programme which offers a range of simple body movements claimed to enhance learning by having a direct effect on the brain. Although the method correctly recognises that learning possibly profits from physical exercise through the improvement of cerebral blood flow, the techniques it offers are exotic, to say the least - not to mention that they hardly make sense from a neuroscientific point of view. For instance, the routine called 'Brain Buttons' for 'improving concentration skills' consists in placing the index and thumb into the slight interdigitations below the collar bone on each side of the sternum, pressing lightly in a pulsing manner, while with the other hand the navel area should be gently pressed (Cohen, 2000). While physical activity has indeed been proven to enhance a range of cognitive functions, from language skills to attention (Courchesne, 1997; Desmond, Gabrieli, Wagner, Ginier, \& Glover, 1997; Kim, Ugurbil, \& Strick, 1994), the 
value of such specific advice, especially when given in a commercial framework, is at least dubious. ${ }^{1}$

Others - maybe disillusioned by such interpretations - expressed pessimism and bluntly claimed that brain-based thinking had nothing new to offer to education (Bruer, 1998). In some sense, and at the present level of our understanding of the central nervous system, this may be true. Studying the literature of the subject, one often has the impression that neuroscience only rediscovers concepts that educators have known for centuries. It would be a mistake, however, to interpret this as evidence that neuroscience will never offer anything new, and one should not fail to recognise its value when it comes to verifying or disproving our long-held concepts on how to teach best.

It must also be noted that education and neuroscience still miss a common language, and it seems reasonable to argue that it will remain so until it is realised that a paradigm shift is necessary. The science / humanities distinction is too rigid to allow cooperation between the two fields. Whoever wants to offer anything new and useful to education from a neuroscientific perspective should be able to formulate neuroscientific questions from classroom problems, which necessitates a proper knowledge of both fields. Furthermore, one cannot expect teachers to understand the message of neuroscience or to properly interpret new findings if their education is rooted only in the humanities. If education really wishes to harvest the fruits of neuroscience, teacher training curricula should provide students opportunity to familiarise themselves with the various aspects of how the nervous system (and the human body) works. Similarly, the neuroscientist who wishes to study problems of education, should not shy away from studying the 'soft sciences'.

All in all, even if neuroscience cannot offer ready-made solutions at the moment, the perspective it offers is worth considering, either to reinforce our existing ideas about

\footnotetext{
${ }^{1}$ No anatomical connection between the intercostal muscles and any part of the brain is known that could mediate such a specific effect, and the same applies to the periumbilical area.
} 
education or to formulate new ones. For a general overview of neuroscience in education, Teaching with the Brain in Mind by Eric Jensen is highly recommended (Jensen, 2005). The present introduction focuses on the social brain.

All learning occurs in a social context, and the social environment (together with the efficacy of social cognition) has a profound effect on the success of learning. It might be said that it is no use teaching until the conditions are not optimal for the social brain. The most obvious example is that of distress. A threatening classroom atmosphere will yield poor learning results, as such an atmosphere generates distress, and distress evokes the fight-or-flight reaction, which is hardly optimal for concentration (Jensen, 2005). The short term effect is sympathetic activation and hypervigility, which leads to an acute inability to concentrate or encode information, but when somebody is exposed to a threatening learning environment for a longer period, more profound and dramatic changes occur. For instance, distress has been shown to reduce the number of new brain cells produced (Gould, McEwen, Tanapat, Galea, \& Fuchs, 1997), to damage the hippocampus (an area of key importance in memory formation), and to cause atrophy of the dendrites- the short processes of neurons (Sousa, Lukoyanov, Madeira, Almeida, \& Paula-Barbosa, 2000). Chronic stress also impairs students' ability to sort out what is important and what is not (Gazzaniga, 1988). Corticosteroids (secreted by the adrenal cortex as part of the stress reaction) reduce the blood flow in the frontal lobes, whereby they indirectly impair verbal and working memory (Lupien, Gillin, \& Hauger, 1999). On the contrary - and on a more positive note-, evidence suggests that an increased positive affect leads to improved felxibility in in behavior and judgment (Ashby, Isen, \& Turken, 1999).

Man is an essentially social being. There is a social aspect to almost anything we do, and it is especially true regarding teaching and learning. It is easy to see that education cannot miss this factor if it wants to be efficient. What follows, therefore, is a brief introduction to the 
social functioning of the human brain, with the purpose of making the reader familiar with the basic concepts.

\section{The Cooperative Spectrum}

Based on the literature of neuroscience, the cooperative spectrum might be defined as a continuous segment of the behavioural repertoire of the individual, which enables one to interact with a given partner between the end points of hostility and cooperation (J. Decety, Jackson, Sommerville, Chaminade, \& Meltzoff, 2004). Figure 1. gives an outline of the cognitive system through which the behaviuoral patterns of the cooperative spectrum are expressed. Each functional element corresponds to more or less well circumscribed areas of the central nervous system (and especially the neocortex). Note that these elements appear on both (or all) cooperating sides, but for reasons of clarity, they have been marked only on one side in the figure. 


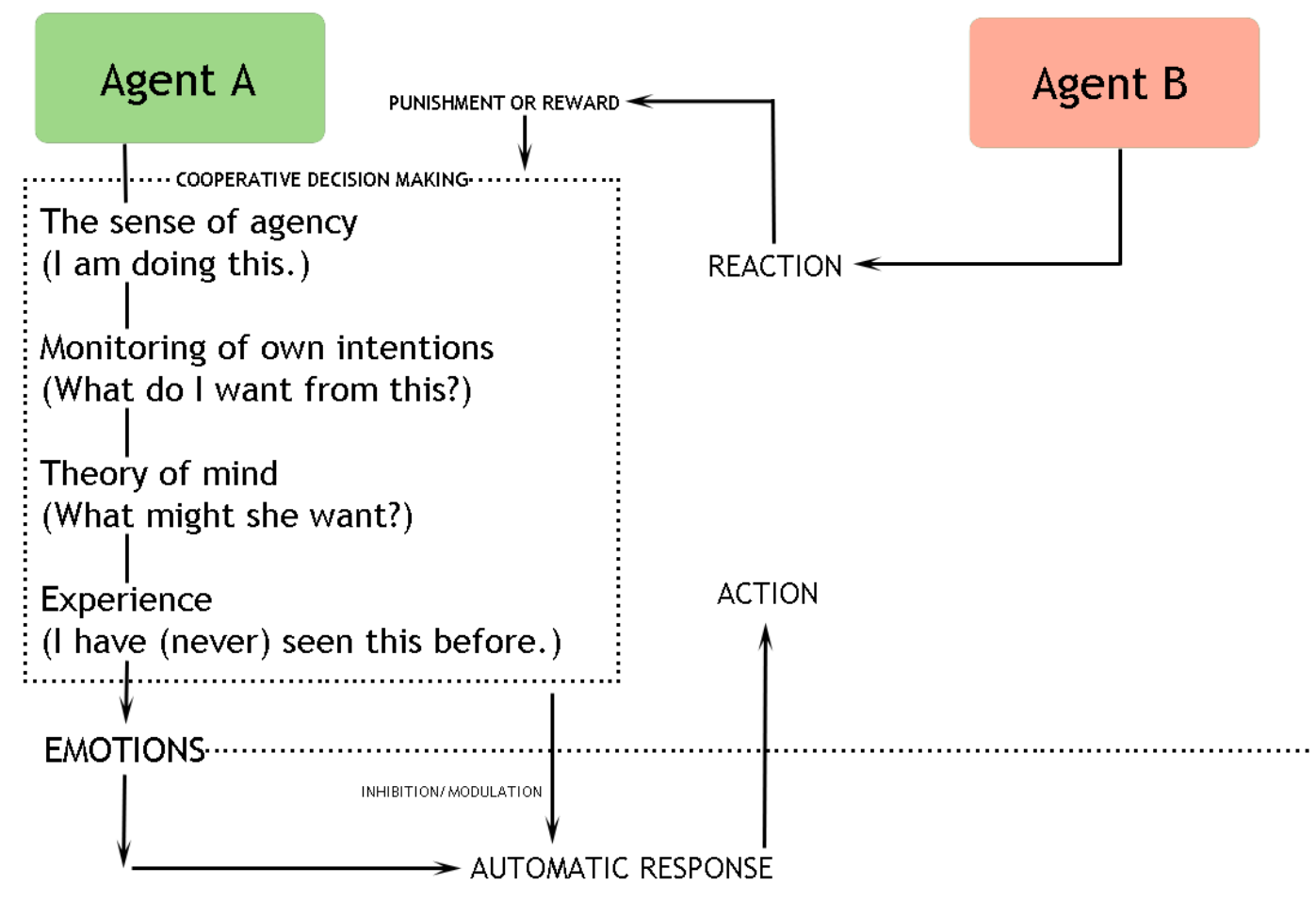

Figure 1. Elements of the cognitive system serving the cooperative spectrum.

First of all, it is essential that the cooperating parties must identify their actions as their own, which is termed the sense of agency (Blakemore \& Frith, 2003; J. Decety et al., 2004). If that requirement is fulfilled, the agent has to assess what their interests are in the given cooperative situation, and this assessment has to be continuously re-done in the process of cooperation. This is possibly done with the help of working memory, mediated by the prefrontal cortex - an area also responsible for the control of impulses and the suppression of responses that are not adequate in the given situation (Pietrini, Guazzelli, Basso, Jaffe, \& Grafman, 2000). A further requirement is that the individual has to know (or at least have a sound estimation of) the intentions, interests and possible reactions of the partner, which is called theory of mind (Brunet, Sarfati, Hardy-Bayle, \& Decety, 2000; Gallagher et al., 2000; 
Goel, Grafman, Sadato, \& Hallett, 1995; Vogeley et al., 2001). Theory of mind largely depends on the previous experiences of the individual, for which the intact functioning of the long term memory systems is essential. The rewarding or aversive value of the actual behaviour can determine if the behaviour is maintained, modified or suspended, therefore the reward-mediating systems of the brain (especially the dopaminergic systems originating in the brainstem and projecting to several cortical areas) also play a key role in cooperative behaviour (J. Decety et al., 2004). Emotions, as mentioned before, do have a profound effect on cognition, and social cognition is not an exception. According to the somatic marker hypothesis of Damasio, emotions are conscious reflections on visceral states, which function as early indicators to help the individual choose the optimal behaviour in a given situation (Damasio, 1996).

In the following we discuss the brain structures underlying these functions. Anatomical terminology is often used, but we believe that this does not affect the intelligibility of the text; also, as this is meant to be an introduction to the field, we found it proper to offer an introduction to the terminology too. For an easier identification of the cortical areas discussed, we also use the histology-based numbering of Brodmann, which is an internationally accepted and used system of orientation on the surface of the brain (e.g. Br.17- the primary visual cortex). Brodmann maps are widely available on the Internet.

\section{I am doing it: Agency}

As said before, the identification of the self as the source of actions is the prerequisite of conscious behaviour. This ability develops by the second postnatal month, but only in an asocial context. Even though by the ninth month of life babies experience themselves also in relation to the others, they do not construct a theory of mind about each other. The reason for this is possibly that the development of the autobiographical self is a prerequisite of 
experiencing oneself as a social agent (Gergely, 2002). The autobiographical self can be interpreted as a component of the self, which helps define the totality of the self by means of long-term memories regarding specifically one's own actions. Autobiographical self, therefore, is dependent on the proper functioning of long-term memory systems. In turn, longterm memory systems are crucial both for the representation of the self and for agency. In fact, the question of the representation of the self in the brain is far from decided; however, given the complexity of the phenomenon, it is most likely that the self emerges as a result of a dynamic interaction between several brain areas, instead of being generated in a separate „self-area” (Newen \& Vogeley, 2003).

As said before, autobiographical self-representation is essential for the representation of the self as different from others. Autobiographical memories, however, presuppose the ability of perceiving oneself as agent. This, in turn, necessitates feedback from one's body about one's actions. Let us take a look at speech as an example. It is assumed that voluntary actions originate in the anterior cingular cortex $(\mathrm{AC}, \mathrm{Br} .32)$ and the dorsolateral prefrontal cortices (DLPFC, Br.9-12, 45-47). When speech as a voluntary action is initiated, these areas activate the speech motor area (or Broca's area, Br. 44-45), but at the same time they send a so-called efferent copy toward the „speech decoding” area (or Wernicke's area, Br.22). This efferent copy reaches Wernicke's area faster than the stimulus of one's own speech sounds, whereby the brain identifies speech as self-generated. The sense of social agency is possibly mediated by similar mechanisms. If the efferent copy mechanism does not work properly, psychopathological states occur, in which the ability to perceive oneself as a distinct identity is (at least partially) lost. An example is auditory hallucination, often seen in schizophrenia, where one perceives one's own thoughts as external commands. It has been hypothesized that in such cases no efferent copy is transmitted to Wernicke's area, ant the theory is known as the disconnection theory of schizophrenia (Friston, 1998). It might be speculated, that the 
earlier described developmental pattern (up to 3 to 5 years of age) reflects the development of this self-monitoring network.

Armed with self-monitoring and the autobiographical self, the individual is ready for selfpositioning in the social space. The inferior temporal cortex (IT, Br. 20) seems to have a key role in this respect (Blakemore \& Frith, 2003). The area is readily activated by tasks forcing the observer to separate actions of one's own from those of others (e.g. when somebody is imitating one's actions), which supports its role in mental self-positioning. Decety and colleagues propose that the representations of the self and others are stored in separate cortical networks, and in different social interactions they might become overlapping to different degrees (J. Decety et al., 2004).

Although we know of no scientifically validated method for the development of selfrepresentation, simple guidelines can be securely determined. First and foremost, the developing child must be given the chance to freely interact with its environment as much as possible, and feedback on these interactions must be given as often as possible. Such feedback helps define the self and also serves as priming for the social feedback system (to be discussed later). Attention should also be paid to the development of the long-term memory, which, as mentioned, is essential for the optimal development of the autobiographical self, but it is not less important that good long-term memory can be a pillar of academic success.

\section{What might they want? - theories of mind and empathy}

Theory of mind is the capacity of creating mental models about the intentions and inner states of our partners. So far two explanations have been proposed for this capacity: the empathy theory and the simulation theory (Goldman, 2006). Empathy theory states that the brain formulates models about interaction partners' inner states by deduction, while the simulation 
theory claims that the brain actually simulates the state the partner is in, making it intelligible this way.

In our opinion, these theories are not absolute explanations, but they rather describe modes of mindreading, both of which are used in different situations. For instance, it seems that simulation is the dominant mode of childhood mindreading (J. M. Decety, M, 2009), and this mode can be especially useful for the recognition of inner states with distinct bodily signs (e.g. facial expressions). Deduction can be dominant in predicting the future intentions and possible reactions of a partner, based on the partner's actual state and previous experiences. Deduction might be especially important when it comes to making predictions about a nonpresent partner.

What do we know about the central nervous system background of theory of mind? Studies on autism offer a valuable insight, as autists seem not to be able to construct theories about other persons' mental states.

Castelli and colleagues examined ten, relatively well functioning autistic adults with computer tomography (Castelli, Frith, Happe, \& Frith, 2002). The target stimuli were animated triangles that apparently influenced each other's trajectory. Triangles were used to minimize the influence of human-specific features and to separate attribution of intention as much as possible. Based on the results of earlier studies (Brunet et al., 2000; Gallagher et al., 2000; Goel et al., 1995; Vogeley et al., 2001), the activation of three areas was analyzed: the anterior cingular cortex (AC, Br. 32), the superior temporal sulcus in the temporoparietal area (Br. 39), and the parts of the temporal lobe surrounding the amygdala. As expected, these areas were found to be suboptimally functioning in autism, which corroborates their putative role as pillars of a theory of mind network.

Rilling an co-workers examined healthy subjects with fMRI in search for the underlying neural network of theory of mind (Rilling, Sanfey, Aronson, Nystrom, \& Cohen, 2004). The 
aim was to map the brain areas that are activated during thinking about the prisoner's dilemma (in this task the greatest gain results from the cooperation of two parties, each of whom has to decide about cooperation without being aware of the partner's intentions). Activation was found in the posterior cingular cortex (Br.23), in the superior temporal sulcus, in the left hippocampus, in an extensive region in the midbrain and in the DLPFC (Br.9-12, 45-47). The DLPFC and the hippocampus are possibly responsible for the cognitive control of the task, while the activation of the cingular cortex and the superior temporal sulcus reflect activity of the theory of mind network, similarly to the study of the Castelli group.

A relatively new discovery, the discovery of mirror neurons, offers an insight into theory of mind at the level of the individual cell (Hunter, Hurley, \& Taber, 2013). These neurons are activated when the activity of the observer is imitated by someone else.

What is known about the development of the brain areas related to theory of mind? It seems that the network takes long to develop, which, at the same time, leaves a wide temporal window for external developmental interventions. For instance, cingular cortex is present already eighteen weeks after gestation (Monteagudo \& Timor-Tritsch, 1997), but its myelination appears to last lifelong (Sowell et al., 2003). A possible interpretation of this finding is that the cingular cortex is dynamically changing throughout the individual's life. The superior temporal sulcus appears approximately at the twenty-third week after gestation (Chi, Dooling, \& Gilles, 1977), and it is the last part of the temporal lobe to myelinate (Gogtay et al., 2004). Its functional development lasts until approximately fourteen years of age (Taylor, Batty, \& Itier, 2004).

There are several interventions through which the development of this system may be enhanced. Of these, we would like to point out learning music (Kalliopuska \& Ruokonen, 1993) and drama play. Although there is no direct neuroscientific evidence on the effects of drama play on the developing brain, we infer that it offers an ideal context for the simulation- 
based development of empathy and theory of mind, as any social situation may be practiced, but without the real-life risks. As it requires active physical involvement, it also helps the development of the sensory and motor areas involved in social interactions. The beneficial effects of learning and playing music are obvious: musical performance requires perfect cooperation between the players, which necessitates an ongoing prediction of the other player's intentions and actions. Furthermore, music requires general cognitive resources too, which play important roles in social cognition. The most obvious example for this may be working memory, which is necessary for playing a piece just as well as for the constant monitoring of a given social situation in relation to one's intentions (see before).

\section{Emotions, impulses, control}

According to Damasio (1996), emotions are conscious interpretations of visceral states, which help us choose the most adaptive behavioral response in any given situation. Such reflexive responses belong to a primitive mode of survival, in which crude representations of the environment evoke crude responses. At lower evolutionary levels, a repertoire of such responses may serve the animal's survival very well, however, in the case of a social species, they are hardly sufficient.

Thus, the development of a system to modulate these reactions was necessary, so that more refined forms of interaction could become possible. This evolutionary development can still be observed in children's social development. Babies react to their environment basically in two ways: they seek pleasant sensations and they withdraw from unpleasant ones - possibly with minimal delay. Socialization is, in fact, the process through which we learn how to suppress or overwrite immediate reactions, how to delay responses and how to express our motifs in finer but still adaptive forms. 
At the level of the nervous system, this means a dynamic interplay between the hypothalamus- pituitary- adrenal gland axis (HPA-axis) and the frontal/prefrontal cortices. Hypofunction of the frontal areas has been reported in killers, and patients who suffered damage to these areas become aggressive and incapable of control their impulses (Pietrini et al., 2000). Decety et al. (2004) observed activation in the orbitofrontal cortex (OFC, Br. $11,12,13,14)$ in cooperative situations, whereby it may be hypothesized that the orbitofrontal cortex plays a role in the inhibition of personal interests when a goal of higher importance is present. It is assumed that OFC integrates socially salient information with (visceral) signals indicating positive or negative outcome, in order to enable the agent to behave in a way that is socially acceptable but still fruitful for the self. OFC, therefore, fulfills a monitoring function too, inasmuch as it has to do regular re-assessment of incoming information so as to be able to generate adaptive output at any time.

The HPA-axis deserves special attention in terms of social behavior, and not only because it mediates several psychosomatic effects. Hypothalamus is the central coordinator of the axis, which integrates input from the body and „decides" if a stress reaction (,fight-or-flight”) might be adaptive in the given situation. If a stress reaction is necessary, the hypothalamus activates the adrenal glands in a hormonal way. Chugani examined socially deprived foster home children and found that their brain development lagged behind that of healthy controls (Chugani et al., 2001). It is assumed that the link is the HPA-axis. Lack of attachment and poor social input act as chronic stressors on the developing nervous system, which results in chronic adrenal overactivation, which, in turn, results in chronically high levels of circulating cortisol (a glucocorticoid hormone produced by the zona fasciculata of the adrenal glands). The hippocampus is rich in glucocorticoid receptors, and this way in chronic stress the hippocampus is chronically overactivated. Evidence suggests (Sapolsky, 1985) that chronically high levels of glucocorticoids are actually toxic to the hippocampus, which can 
explain why chronic stress interferes so markedly with brain development. As social deprivation also prevents the development of social impulse control, the net result is deficient social function with learning deficits (as the hippocampus is a key structure in learning).

Important as they may be, the HPA axis and the limbic system are not accessible for voluntary development, but - as they also control vital functions - manipulation with them would not be desirable anyway. Therefore, the enhancement of impulse control must happen through the inhibitory structure, the (pre)frontal cortex. The good news is that plenty of time seems to be available for this: there is evidence that this area of the brain is still in development at the age of 23 .

To understand how certain means of development may enhance social functions in the human brain, it is useful to consider the theory of neuronal recycling. The theory claims that a given brain area (population of neurons) may serve multiple purposes at the same time, whereby damage to an area results in deficits in all the functions the given area fulfills. Similarly, we assume that the brain processes social information by utilizing the same simple operations as in the case of non-social processing. For instance, the conditioning feedback is the same, regardless of whether the source of reinforcement is human or non-human. An enjoyable activity stimulates the same reward areas as a person whom one finds pleasant, and the result in both cases is that the agent will seek the stimulus more frequently.

Practically, this means that the development of some simple, prefrontally localized functions can have a beneficial effect on the prefrontally localized social functions as well. There are several such functions, but working memory may be the most important of them (it is certainly the most often studied and best known one). Working memory plays a crucial role in rule-regulated processes (such as various social situations), where it keeps the rules on standby to compare the actual state of events to them. Generally speaking, working memory serves as a monitor, which compares the actual state to an ideal state (as defined by the rules). 
To enhance this monitoring function, any kind of rule-based task might be useful. The social benefit is an enhanced ability to assess social situations in terms of the rules and also one's own goals and intentions. Although it is not a task designed for developmental purposes, the Rutgers Acquired Equivalence Test (Myers et al., 2003) offers a good example of a childfriendly task relying on the working memory.

\section{Positive and negative feedback systems}

Social contacts are rewards. Physiologically, we are dependent on social contacts, which is reflected in the fact that social contacts activate the same areas as substances of abuse or gambling. The evolutionary meaning of this is that without a proper support from our peers, our survival is at risk, even in modern societies.

Mayes and co-workers name the amygdala, the hippocampus, the prefrontal cortices, the nucleus accumbens and the ventral tegmental area of the brainstem as parts of the reward system (Mayes, 2009). Of these, the hippocampus is possibly not a reward structure in the direct sense, rather, it plays a role in forming memories about the reward/punishment value of partners. As for assigning reward value to partners, the ventral tegmentum- prefrontal cortex axis seems to be the key system. As the ventral tegmentum projects on the prefrontal areas, dopamine (a potent excitatory neurotransmitter) released by this structure can enhance associations there by reinforcing synaptic connections. Possibly this is the way a „rule” is formed regarding the value of a partner, which can later be utilized by memory systems.

A parallel system, the nucleus accumbens- striatum system serves the same purpose subcortically, and it is possibly the emotional counterpart of the ventral tegmentum-prefrontal cortex axis. Nucleus accumbens is a subcortical nucleus, that is, a population of neurons (gray matter) embedded in the white matter, under the cortex. Striatum is a complex of two similar nuclei, the caudate nucleus and the putamen. Nucleus accumbens is also a dopaminergic 
nucleus, and it releases dopamine in the striatum. This seems to be associated with motivation, reward and the learning of new behavioral patterns (Ito, Dalley, Robbins, \& Everitt, 2002; Masterman \& Cummings, 1997).

Of course, a partner can also have aversive value. The amygdala (a group of thirteen connected subcortical nuclei) is assumed to play a key role in such negative associations. The amygdala has been shown to mediate both social and non-social fear (Davis, Walker, \& Lee, 1997; Hariri, Mattay, Tessitore, Fera, \& Weinberger, 2003; LeDoux, 1998), the identification of facial expressions associated with fear (Morris et al., 1996), and in judgments about whether a partner is reliable (Winston, Strange, O'Doherty, \& Dolan, 2002). In this latter sense, the amygdala plays a role in the theory of mind network too. All in all, amygdala is a general danger detector, which - in agreement with the neuronal recycling theory - also functions as a social danger detector.

The development of the frontal areas was described earlier, and the development of most of the subcortical areas is poorly understood. Therefore, we discuss here only the development of the amygdala. The human amygdala is discernible at the fifth week after the gestation, and in the following two weeks the thirteen subnuclei also develop (Humphrey, 1968). It is at about 10 months after birth that the amygdala's connectivity with various parts of the cortex is adult-like (Brody, Kinney, Kloman, \& Gilles, 1987; Kinney, Brody, Kloman, \& Gilles, 1988). It is interesting to note that psychology has long recognized the tenth postnatal month as the time when separation anxiety first develops. As for the size of the nucleus, the amygdala exhibits sexual dimorphism: boys' amygdala is larger (Durston et al., 2001), and it undergoes rapid growth between the ages 8-14 (Giedd, Castellanos, Rajapakse, Vaituzis, \& Rapoport, 1997). At the moment no means of the functional enhancement of the amygdala is known. 


\section{Closing remarks}

In this brief study we have made an attempt to introduce the reader to the neural substrates of certain elements of social behavior. We hope that this study can be a good starting point for the researcher of education who is interested in the underlying biological processes of various social phenomena. We believe that even if the development of a biologically supported education is at a very early stage, the future of education lies in integrating science and the humanities.

\section{References}

Ashby, F. G., Isen, A. M., \& Turken, A. U. (1999). A neuropsychological theory of positive affect and its influence on cognition. Psychol Rev, 106(3), 529-550.

Blakemore, S. J., \& Frith, C. (2003). Self-awareness and action. [Research Support, Non-U.S. Gov't

Review]. Curr Opin Neurobiol, 13(2), 219-224.

Brody, B. A., Kinney, H. C., Kloman, A. S., \& Gilles, F. H. (1987). Sequence of central nervous system myelination in human infancy. I. An autopsy study of myelination. J Neuropathol Exp Neurol, 46(3), 283-301.

Bruer, J. (1998). Brain science, brain fiction. Educational Leadership, 56(3), 14-18.

Brunet, E., Sarfati, Y., Hardy-Bayle, M. C., \& Decety, J. (2000). A PET investigation of the attribution of intentions with a nonverbal task. Neuroimage, 11(2), 157-166. doi: 10.1006/nimg.1999.0525

Castelli, F., Frith, C., Happe, F., \& Frith, U. (2002). Autism, Asperger syndrome and brain mechanisms for the attribution of mental states to animated shapes. Brain, 125(Pt 8), 18391849.

Chi, J. G., Dooling, E. C., \& Gilles, F. H. (1977). Gyral development of the human brain. Ann Neurol, 1(1), 86-93. doi: 10.1002/ana.410010109

Chugani, H. T., Behen, M. E., Muzik, O., Juhasz, C., Nagy, F., \& Chugani, D. C. (2001). Local brain functional activity following early deprivation: a study of postinstitutionalized Romanian orphans. Neuroimage, 14(6), 1290-1301. doi: 10.1006/nimg.2001.0917

Cohen, I. G., M. . (2000). Hands On: How to Use BrainGym in the Classroom. Sea Point, South Africa: Hands On Books.

Courchesne, E. A., G. (1997). Prediction and preparation, fundamental functions of the cerebellum. Learning and Memory, 4, 1-35.

Damasio, A. R. (1996). The somatic marker hypothesis and the possible functions of the prefrontal cortex. [Research Support, U.S. Gov't, P.H.S.

Review]. Philosophical Transactions of the Royal Society of London. Series B: Biological Sciences, 351(1346), 1413-1420. doi: 10.1098/rstb.1996.0125

Davis, M., Walker, D. L., \& Lee, Y. (1997). Roles of the amygdala and bed nucleus of the stria terminalis in fear and anxiety measured with the acoustic startle reflex. Possible relevance to PTSD. Ann N Y Acad Sci, 821, 305-331.

Decety, J., Jackson, P. L., Sommerville, J. A., Chaminade, T., \& Meltzoff, A. N. (2004). The neural bases of cooperation and competition: an fMRI investigation. Neuroimage., 23(2), 744-751.

Decety, J. M., M. (2009). Imitation As A Stepping Stone to Empathy. In M. G. DeHaan, M R (Ed.), Handbook of Developmental Social Neuroscience. New York: The Guilford Press. 
Desmond, J. E., Gabrieli, J. D., Wagner, A. D., Ginier, B. L., \& Glover, G. H. (1997). Lobular patterns of cerebellar activation in verbal working-memory and finger-tapping tasks as revealed by functional MRI. [Research Support, Non-U.S. Gov't

Research Support, U.S. Gov't, P.H.S.]. J Neurosci, 17(24), 9675-9685.

Durston, S., Hulshoff Pol, H. E., Casey, B. J., Giedd, J. N., Buitelaar, J. K., \& van Engeland, H. (2001). Anatomical MRI of the developing human brain: what have we learned? J Am Acad Child Adolesc Psychiatry, 40(9), 1012-1020. doi: 10.1097/00004583-200109000-00009

Friston, K. J. (1998). The disconnection hypothesis. Schizophr Res, 30(2), 115-125.

Gallagher, H. L., Happe, F., Brunswick, N., Fletcher, P. C., Frith, U., \& Frith, C. D. (2000). Reading the mind in cartoons and stories: an fMRI study of 'theory of mind' in verbal and nonverbal tasks. Neuropsychologia, 38(1), 11-21.

Gazzaniga, M. (1988). Mind matters: How mind and brain interact to create our conscious lives. Boston: Houghton-Mifflin/MIT Press.

Gergely, G. (2002). The development of understanding self and agency. In U. Goswami (Ed.), Blackwell handbook of childhood cognitive development. Malden: Blackwell Publishing.

Giedd, J. N., Castellanos, F. X., Rajapakse, J. C., Vaituzis, A. C., \& Rapoport, J. L. (1997). Sexual dimorphism of the developing human brain. [Clinical Trial]. Prog Neuropsychopharmacol Biol Psychiatry, 21(8), 1185-1201.

Goel, V., Grafman, J., Sadato, N., \& Hallett, M. (1995). Modeling other minds. [Clinical Trial

Randomized Controlled Trial]. Neuroreport, 6(13), 1741-1746.

Gogtay, N., Giedd, J. N., Lusk, L., Hayashi, K. M., Greenstein, D., Vaituzis, A. C., . . Thompson, P. M. (2004). Dynamic mapping of human cortical development during childhood through early adulthood. Proc.Natl.Acad.Sci.U.S.A., 101(21), 8174-8179.

Goldman, A. I. (2006). Simulating Minds. The Philosophy, Psychology and Neuroscience of Mindreading. New York: OUP.

Gould, E., McEwen, B. S., Tanapat, P., Galea, L. A., \& Fuchs, E. (1997). Neurogenesis in the dentate gyrus of the adult tree shrew is regulated by psychosocial stress and NMDA receptor activation. [Research Support, Non-U.S. Gov't

Research Support, U.S. Gov't, P.H.S.]. J Neurosci, 17(7), 2492-2498.

Gross, C. G. (1995). Aristotle on the Brain. The Neuroscientist, 1, 245-250.

Hariri, A. R., Mattay, V. S., Tessitore, A., Fera, F., \& Weinberger, D. R. (2003). Neocortical modulation of the amygdala response to fearful stimuli. Biol Psychiatry, 53(6), 494-501.

Humphrey, T. (1968). The development of the human amygdala during early embryonic life. J Comp Neurol, 132(1), 135-165. doi: 10.1002/cne.901320108

Hunter, S., Hurley, R. A., \& Taber, K. H. (2013). A look inside the mirror neuron system. $J$ Neuropsychiatry Clin Neurosci, 25(3), 171-175. doi: 10.1176/appi.neuropsych.13060128

Ito, R., Dalley, J. W., Robbins, T. W., \& Everitt, B. J. (2002). Dopamine release in the dorsal striatum during cocaine-seeking behavior under the control of a drug-associated cue. [Research Support, U.S. Gov't, P.H.S.]. J Neurosci, 22(14), 6247-6253. doi: 20026606

Jensen, E. (2005). Teaching with the Brain in Mind (2nd ed.). Alexandria, VA: Association for Supervision and Curriculum Development.

Kalliopuska, M., \& Ruokonen, I. (1993). A study with a follow-up of the effects of music education on holistic development of empathy. Percept Mot Skills, 76(1), 131-137.

Kim, S. G., Ugurbil, K., \& Strick, P. L. (1994). Activation of a cerebellar output nucleus during cognitive processing. Science, 265(5174), 949-951.

Kinney, H. C., Brody, B. A., Kloman, A. S., \& Gilles, F. H. (1988). Sequence of central nervous system myelination in human infancy. II. Patterns of myelination in autopsied infants. $J$ Neuropathol Exp Neurol, 47(3), 217-234.

LeDoux, J. (1998). Fear and the brain: where have we been, and where are we going? Biol Psychiatry, 44(12), 1229-1238.

Lupien, S. J., Gillin, C. J., \& Hauger, R. L. (1999). Working memory is more sensitive than declarative memory to the acute effects of corticosteroids: a dose-response study in humans. Behav Neurosci, 113(3), 420-430.

Masterman, D. L., \& Cummings, J. L. (1997). Frontal-subcortical circuits: the anatomic basis of executive, social and motivated behaviors.J Psychopharmacol, 11(2), 107-114. 
Mayes, L. C. M., J ;Lejuez, C W; Nicholls, S S. (2009). Social Relationships as Primary Rewards: The Neurobiology of Attachment. In M. G. deHaan, M R (Ed.), Developmental Social Neuroscience. London, New York: The Guilford Press.

Monteagudo, A., \& Timor-Tritsch, I. E. (1997). Development of fetal gyri, sulci and fissures: a transvaginal sonographic study. Ultrasound Obstet Gynecol, 9(4), 222-228. doi: 10.1046/j.1469-0705.1997.09040222.x

Morris, J. S., Frith, C. D., Perrett, D. I., Rowland, D., Young, A. W., Calder, A. J., \& Dolan, R. J. (1996). A differential neural response in the human amygdala to fearful and happy facial expressions. Nature, 383(6603), 812-815. doi: 10.1038/383812a0

Myers, C. E., Shohamy, D., Gluck, M. A., Grossman, S., Kluger, A., Ferris, S., . . Schwartz, R. (2003). Dissociating hippocampal versus basal ganglia contributions to learning and transfer. $J$ Cogn Neurosci, 15(2), 185-193. doi: 10.1162/089892903321208123

Newen, A., \& Vogeley, K. (2003). Self-representation: searching for a neural signature of selfconsciousness. Conscious Cogn, 12(4), 529-543.

Pietrini, P., Guazzelli, M., Basso, G., Jaffe, K., \& Grafman, J. (2000). Neural correlates of imaginal aggressive behavior assessed by positron emission tomography in healthy subjects. Am.J.Psychiatry., 157(11), 1772-1781.

Rilling, J. K., Sanfey, A. G., Aronson, J. A., Nystrom, L. E., \& Cohen, J. D. (2004). The neural correlates of theory of mind within interpersonal interactions. Neuroimage, 22(4), 1694-1703. doi: 10.1016/j.neuroimage.2004.04.015

Sapolsky, R. M. (1985). A mechanism for glucocorticoid toxicity in the hippocampus: increased neuronal vulnerability to metabolic insults. J Neurosci, 5(5), 1228-1232.

Sousa, N., Lukoyanov, N. V., Madeira, M. D., Almeida, O. F., \& Paula-Barbosa, M. M. (2000). Reorganization of the morphology of hippocampal neurites and synapses after stress-induced damage correlates with behavioral improvement. Neuroscience, 97(2), 253-266.

Sowell, E. R., Peterson, B. S., Thompson, P. M., Welcome, S. E., Henkenius, A. L., \& Toga, A. W. (2003). Mapping cortical change across the human life span. Nat Neurosci, 6(3), 309-315. doi: $10.1038 / \mathrm{nn} 1008$

Taylor, M. J., Batty, M., \& Itier, R. J. (2004). The faces of development: a review of early face processing over childhood. J Cogn Neurosci, 16(8), 1426-1442. doi: $10.1162 / 0898929042304732$

Vogeley, K., Bussfeld, P., Newen, A., Herrmann, S., Happe, F., Falkai, P., . . Zilles, K. (2001). Mind reading: neural mechanisms of theory of mind and self-perspective. Neuroimage, $14(1 \mathrm{Pt} 1)$, 170-181. doi: 10.1006/nimg.2001.0789

Winston, J. S., Strange, B. A., O'Doherty, J., \& Dolan, R. J. (2002). Automatic and intentional brain responses during evaluation of trustworthiness of faces. Nat Neurosci, 5(3), 277-283. doi: $10.1038 / \mathrm{nn} 816$ 